\title{
Isolation and Antibiogram of Staphylococcus aureus from Powdered Milk sold in Samaru Market, Zaria
}

*Madika, A., Musa, B., Sulaiman, M.A., Hussaini, I.M. and Jimmy, G.G. Department of Microbiology, Faculty of Life Sciences, Ahmadu Bello University, Zaria-Nigeria "Correspondence:abubakarmadika@gmail.com , amadika@abu.edu.ng, +2347061587391

\begin{abstract}
Milk is a nutritive food that serves as an excellent growth medium for wide variety of microbes. This study was conducted to determine the occurrence of Staphylococcus aureus in powdered milk sold in Samaru market, Zaria, and their antibiotic susceptibility patterns. Fifty (50) powdered milk samples were collected from different shop vendors. The samples were used for isolation of Staphylococcus aureus by cultural method. Staphylococcal count was determined and the colonies observed were identified based on colonial morphology, microscopic and biochemical characterization. The antibiogram of the isolates were also determined using Kirby-Bauer disc diffusion method. The highest Staphylococcal mean count of $1.47 \times 10^{4} \mathrm{CFU} / \mathrm{g}$ was observed in powdered milk samples displayed outside the shop in sacks and the lowest count of $1.22 \times 10^{4} \mathrm{CFU} / \mathrm{g}$ was observed for samples displayed inside the shop in sacks. Fifteen (15) samples were positive for Staphylococcus aureus giving a percentage occurrence of $30 \%$, with samples displayed outside the shop in sacks having the highest occurrence (42.9\%) while the least (16.67\%) occurrence was observed in those displayed inside the shop in sacks. The antibiogram revealed a high susceptibility to Ciprofloxacin (100\%), Gentamicin (93.33\%), Erythromycin and Chloramphenicol (73.33\%). While other isolates showed high resistance to Norfloxacin (66.67\%) and Ampicillin-cloxacillin (26.67\%). Five (5) isolates were resistant to multiple antibiotics with multiple antibiotic resistance index (MARI) ranging from 0.3-0.4. The study revealed high occurrence of Staphylococcus aureus in powdered milk and its resistance to commonly used antibiotics possess a public health risk to consumers of these products
\end{abstract}

Keywords: Isolation, Powdered milk, Staphylococcus aureus, Antibiogram, Multiple antibiotic resistance index (MARI)

INTRODUCTION

Milk is an important source of nutrients critical for the proper development as well as the maintenance of the human body (Bashar and Malek, 2006). It is a nutritive food that serves as an excellent growth medium for a wide variety of microbes. Some of the factors that affect the microbiological quality of milk include the initial raw milk flora, the processing conditions, and contamination after heat treatment (Ahmed and Anwar, 2006) during either packaging or handling.

A large number of microorganisms have been implicated in the spoilage of milk and dairy products including lactic acid bacteria, coliforms, Gram negative psychrotrophs, molds, and yeasts. Other bacteria of public health concern such as Campylobacter jejuni, Listeria monocytogenes, and Salmonella spp., pathogenic strains of $E$. coli, Yersinia enterocolitica, and enterotoxigenic Staphylococcus aureus may be found in milk and milk products (Agboke et al., 2011). Pathogenic bacteria in milk and milk products have been a major concern for public health since the early days of the dairy industry as many diseases can be transmitted through consumption of these products (Van Kessel et al., 2004).

The ability of bacteria to cause food-borne poisoning solely depends on toxin production after ingestion or ingestion of preformed toxins in food. Among the bacteria primarily involved, Staphylococcus aureus is prominent, causing gastroenteritis due to consumption of contaminated food. Staphylococcal food poisoning results due to consumption of staphylococcal enterotoxins preformed in foods (Loir et al., 2003). It has been reported as the third cause of food-borne illnesses in the world with major foods implicated to be milk, dairy products, and meats, particularly handled foods playing vital roles (Ateba et al., 2010).

Powdered milk can sometimes be contaminated with pathogenic microbes but due to low moisture content it does not allow their growth but can remain viable for long periods. Consequently, they do not play direct role in their spoilage. However, if the milk is subjected to time-temperature abuse after rehydration, such organisms may multiply and subsequently causes illness. 


\section{UJMR, Volume 5 Number 1, June, 2020, pp 77 - 81 ISSN: 2616-0668}

Therefore, their occurrence is of great importance as they serve as an index of hygienic standards during production, processing, packaging, handling, and retailing (Wouters et al., 2002).

Consumption of unpackaged powdered milk poses a health risk to consumers as the milk stands a high risk of contamination through nasal passages, frequent contact with hands via which $S$. aureus can be introduced by being a normal flora of the body (Ayele et al., 2017). This study therefore investigates the bacteriological quality of unpackaged powdered milk sold in Samaru community market, ZariaKaduna State and to isolate Staphylococcus aureus from the powdered milk and to determine their antibiotic susceptibility patterns.

\section{MATERIALS AND METHODS}

\section{Study Area}

The study area was Samaru community Market Zaria, Sabon Gari local government area, Kaduna State-Nigeria. Samaru is located on latitude $11^{\circ} 09^{\prime} 30.99{ }^{\prime} \mathrm{N}$ and longitude $7^{\circ} 38^{\prime} 15.68$ to $7^{\circ} 39^{\prime} 20.68^{\prime \prime} \mathrm{E}$ at an altitude of $550-700 \mathrm{~m}$. It lies within the Northern Guinea savanna vegetation belt (Aboh et al., 2015). The Market is patronized by members of the local community and neighboring villages.

\section{Collection of Samples}

A total of 50 powdered milk samples were collected from different vendors, taking note of the samples method of display at retail point. The samples were packaged in a clean polythene bag, labelled appropriately and transported to the Main Teaching Laboratory, Department of Microbiology, Ahmadu Bello University, Zaria for analysis.

\section{Preparation of Media}

The media used were of analytical grade(Oxoid $\left.{ }^{T M}, U K\right)$ and includes mannitol salt agar (MSA), nutrient agar (NA), Mueller-Hinton agar, deoxyribonuclease agar (DNase agar), and buffered peptone water. All the media were prepared according to the manufacturers' instructions.

\section{Enumeration and Isolation of Staphylococcus} aureus

This was carried out according to the procedure described by Afroz et al. (2013). Twenty five $(25 \mathrm{~g})$ of the powdered milk was added to $225 \mathrm{~mL}$ of sterile normal saline and mixed thoroughly. A tenfold serial dilution to $10^{-5}$ was carried out, and $0.1 \mathrm{~mL}$ of the $10^{-4}$ dilution was spread-inoculated onto mannitol salt agar. The plates were incubated aerobically at $37^{\circ} \mathrm{C}$ for 24hours. Appearances of golden yellow colonies were presumptively considered to be Staphylococcus aureus. The observed colonies characteristics of S. aureus were counted. All counts were expressed as colony forming units per gram (CFU/g). Colonies were picked and stored on nutrient agar slants for further confirmation tests.

\section{Characterization of Isolates}

Presumptive Staphylococcus species were Gram stained and the Gram positive cocci in clusters were subjected to biochemical characterization using catalase, coagulase, and DNase tests as described by Cheesbrough (2009).

\section{Antibiotic Susceptibility Test}

The antibiotic susceptibility tests for the isolates were performed by Kirby-Bauer (disc diffusion) method. Isolates were grown on nutrient agar for 24 hours and colonies suspended in $2 \mathrm{~mL}$ sterile normal saline until a turbidity equivalent to 0.5 MacFarland standards was obtained. A $0.1 \mathrm{~mL}$ aliquot of each bacterial suspension was separately inoculated on freshly prepared Mueller-Hinton agar with the aid of sterile swabs to form a bacterial lawn (Okpo et al., 2016). Standard antibiotic discs were then placed on the inoculated plates equidistant from each other and pressed gently using sterile forceps to ensure contact with the agar surface. The plates were then allowed to stand for 15 minutes pre-diffusion time and then incubated aerobically at $37^{\circ} \mathrm{C}$ for 24 hours. The diameter of zones of inhibition were measured to the nearest millimetre and isolates were characterized as susceptible, intermediate or resistant to the antibiotic used in reference to the interpretation standards provided by CLSI (2015). The antibiotics used were; Norfloxacin

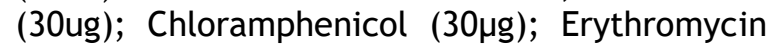

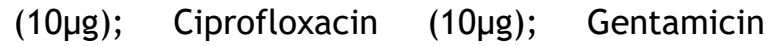
$(10 \mu \mathrm{g})$; Streptomycin $(30 \mu \mathrm{g})$; and Ampicillincloxacillin $(20 \mu \mathrm{g})$.

\section{RESULTS}

Staphylococcal count of the powdered milk samples was determined, with samples displayed outside the shop in sacks having the highest mean count $\left(1.47 \times 10^{4} \mathrm{CFU} / \mathrm{g}\right)$. Whereas, the least mean count $\left(1.22 \times 10^{4} \mathrm{CFU} / \mathrm{g}\right)$ was observed in samples displayed inside the shop in sack (Table 1).

Out of the total of 50 powdered milk samples examined, fifteen isolates were confirmed to be $S$. aureus based on colonial, microscopic and biochemical characteristics (Table 2). An overall percentage occurrence of $30 \%$ of $S$. aureus was observed in this study, with samples displayed outside the shop in sacks having the highest occurrence of $42.9 \%$ while the least $(16.67 \%)$ observed in those displayed inside the shop in sacks (Table 3). 
UJMR, Volume 5 Number 1, June, 2020, pp 77 - $81 \quad$ ISSN: $2616-0668$

The antibiotic susceptibility pattern of the isolates is presented in Table 4 . The isolates showed $100 \%, 93.33 \%$, and $73.33 \%$ susceptibility to Ciprofloxacin, Gentamicin, and Erythromycin and Chloramphenicol respectively. A total of five (5) isolates were resistant to two or more antibiotics (Table 5), with MAR Index ranging from $0.3-0.4$.

Table 1: Staphylococcal Count of Powdered Milk in Relation to Methods of Display

\begin{tabular}{lcccc} 
Methods of Display & Number of Samples & $\begin{array}{c}\text { Counts Range } \\
(\text { CFU/g) }\end{array}$ & $\begin{array}{c}\text { Mean counts } \\
\text { (CFU/g) }\end{array}$ & $\begin{array}{l}{ }^{*} \text { Permissible } \\
\text { Limit }\end{array}$ \\
\hline TPB & 16 & $44-230 \times 10^{4}$ & $1.38 \times 10^{4}$ & \\
OSS & 14 & $10-412 \times 10^{4}$ & $1.47 \times 10^{4}$ & $<10^{2} \mathrm{CFU} / \mathrm{g}$ \\
ISS & 12 & $16-400 \times 10^{4}$ & $1.22 \times 10^{4}$ & \\
IRB & 8 & $91-320 \times 10^{4}$ & $1.27 \times 10^{4}$ & \\
\hline
\end{tabular}

Key: TPB: Tied in a polythene bag, OSS: Outside the shop in a sack, ISS: Inside the shop in a sack, IRB: Inside a rubber bucket; *Food Standards Australia New Zealand 2018

Table 2: Cultural, Microscopic and Biochemical Characteristics of Staphylococcus Isolates

\begin{tabular}{|c|c|c|c|c|c|c|}
\hline \multirow[b]{2}{*}{$\begin{array}{l}\text { Isolate's } \\
\text { code }\end{array}$} & \multirow[b]{2}{*}{ Growth on MSA } & \multirow[b]{2}{*}{ GRM } & \multicolumn{3}{|c|}{ Biochemical characteristics } & \multirow[b]{2}{*}{ Inference } \\
\hline & & & $\begin{array}{r}\text { Cat } \\
\text { DNase }\end{array}$ & Coa & & \\
\hline SM1 & Golden yellow colonies & G+ve cocci & +ve & $+\mathrm{ve}$ & + ve & S. aureus \\
\hline SM2 & Golden yellow colonies & G+ve cocci & + ve & + ve & + ve & S. aureus \\
\hline SM8 & Golden yellow colonies & G+ve cocci & + ve & + ve & + ve & S. aureus \\
\hline SM9 & Golden yellow colonies & G+ve cocci & + ve & + ve & + ve & S. aureus \\
\hline SM13 & Golden yellow colonies & G+ve cocci & + ve & +ve & + ve & S. aureus \\
\hline SM15 & Golden yellow colonies & G+ve cocci & + ve & + ve & + ve & S. aureus \\
\hline SM20 & Golden yellow colonies & G+ve cocci & + ve & + ve & + ve & S. aureus \\
\hline SM21 & Golden yellow colonies & G+ve cocci & + ve & + ve & + ve & S. aureus \\
\hline SM22 & Golden yellow colonies & G+ve cocci & + ve & + ve & + ve & S. aureus \\
\hline SM25 & Golden yellow colonies & G+ve cocci & + ve & + ve & + ve & S. aureus \\
\hline SM34 & Golden yellow colonies & G+ve cocci & + ve & +ve & + ve & S. aureus \\
\hline SM42 & Golden yellow colonies & G+ve cocci & + ve & + ve & + ve & S. aureus \\
\hline SM46 & Golden yellow colonies & G+ve cocci & + ve & + ve & + ve & S. aureus \\
\hline SM48 & Golden yellow colonies & G+ve cocci & + ve & + ve & + ve & S. aureus \\
\hline SM50 & Golden yellow colonies & G+ve cocci & +ve & + ve & +ve & S. aureus \\
\hline
\end{tabular}

Key:SM: Samaru Market; MSA:Mannitol Salt Agar; GRM: Gram Reaction and Morphology; DNase: Deoxyribonuclease test; Cat: catalase test; Coa: coagulase test; G+ve: Gram positive; +ve: positive

Table 3: Distribution of Staphylococcus aureus with Respect to Methods of Sample Display

\begin{tabular}{lcc}
\hline Methods of Display & Number of Samples & Number Positive \\
\hline TPB & 16 & $4(25)$ \\
OSS & 14 & $6(42.9)$ \\
ISS & 12 & $2(16.67)$ \\
IRB & 8 & $3(37.5)$ \\
Total & 50 & $15(30.0)$ \\
\hline
\end{tabular}

Key: TPB: Tied in a polythene bag; OSS: Outside the shop in a sack; ISS: Inside the shop in a sack; IRB: Inside a rubber bucket

Table 4: Antibiotic Susceptibility Pattern of Staphylococcus aureus Isolated from Powdered Milk

\begin{tabular}{lccc} 
& & Number of Isolates $(\%)$ & Resistant \\
\cline { 3 - 4 } Antibiotics $(\mu \mathrm{g})$ & Susceptible & Intermediate & $1(6.67)$ \\
Gentamycin $(10)$ & $14(93.33)$ & $0(0.00)$ & $0(0)$ \\
Ciprofloxacin (10) & $15(100)$ & $0(0.00)$ & $10(66.67)$ \\
Norfloxacin (30) & $4(26.67)$ & $1(6.67)$ & $0(0)$ \\
Erythromycin (10) & $11(73.33)$ & $4(26.67)$ & $4(26.67)$ \\
Ampicillin-cloxacillin $(20)$ & $6(40)$ & $5(33.33)$ & $1(6.67)$ \\
Chloramphenicol (30) & $11(73.33)$ & $3(20.00)$ & $1(6.67)$ \\
Streptomycin (30) & $8(53.33)$ & $6(40.00)$ & \\
\hline
\end{tabular}

Key: $\mu$ g: Micrograms 
Table 5: Multiple Antibiotic Resistance Indices (MARI) of Staphylococcus aureus Isolated from Powdered Milk

\begin{tabular}{lccc}
\multicolumn{4}{c}{$\mathbf{n = 7}$} \\
\hline Isolate's Code & Number of Antibiotic Resisted & Resistance Pattern & MAR Index \\
\hline SM1 & 2 & NB, CH & 0.3 \\
SM20 & 3 & NB, APX, S & 0.4 \\
SM21 & 2 & NB, APX & 0.3 \\
SM25 & 2 & NB, APX & 0.3 \\
SM50 & 2 & NB, APX & 0.3 \\
\hline
\end{tabular}

Key:SM: Samaru Market; NB: Norfloxacin; APX: Ampicillin-cloxacillin; CH: Chloramphenicol; S: Streptomycin; n: number of antibiotics tested

\section{DISCUSSION}

The staphylococcal counts of the powdered milk samples examined in this study with respect to their methods of display at retail point revealed high counts. These high counts observed for all the samples irrespective of their methods of display might be attributed to post-processing contamination due to low hygienic practices of the retailers. This might have led to the introduction of staphylococci into the products via direct contact by hands or respiratory secretions as the organism is a normal flora of the skin, throat, and nasal passages. The staphylococcal count of the powdered milk samples exceeded the satisfactory limit of $<10^{2} \mathrm{CFU} / \mathrm{g}$ by the Food Standards Australia New Zealand (2018). Afroz et al. (2013) also reported staphylococcal range counts of $1.5 \times 10^{2}-3.6 \times 10^{3} \mathrm{CFU} / \mathrm{g}$ in full cream powdered milk sold under market conditions in Dhaka, Bangladesh.

A high percentage occurrence of $30 \%$ of Staphylococcus aureus was observed in this study. This indicates that consumption of this contaminated powdered milk has potential health risks to the consumers and may be a possible source of food borne illnesses for the consumers of these products in and around the study location.

Resistance of pathogenic microbes against antibiotics is a major concern globally, as it leads to failures in treatment of human and animal diseases. The Staphylococcus aureus isolates showed high susceptibilities to ciprofloxacin, gentamicin, erythromycin, and chloramphenicol. These observed susceptibilities might be due to their molecular sizes, a factor which increases their solubility in diluents and consequently further their penetration ability through cell wall into the cytoplasm of the target organism (Mailard,
2002; Poole, 2002). However, the isolates were observed to be highly resistant to norfloxacin, and moderately resistant to Ampicillincloxacillin. The resistance observed could be attributed to antibiotic abuse inform of over use and misuse of antibiotic. The antibiotic susceptibility patterns observed in this study is similar to the observations reported by Okpo et al. (2016).

MAR index observed in this study ranged between 0.3-0.4. A MAR index greater than 0.2 shows a high risk source of contamination where antibiotics are frequently used (Furtula et al., 2013). The MAR index observed among the Staphylococcus aureus isolates might be due to over the counter usage of antibiotics, and self-medication.

\section{CONCLUSION}

An overall occurrence of $30 \%$ of Staphylococcus aureus from powdered milk was observed in this study, and this poses a health threat for the consumers of this product. Antibiogram of the Staphylococcus aureus isolates revealed high susceptibilities to ciprofloxacin, gentamicin, erythromycin, and chloramphenicol, while resistance was observed against norfloxacin and ampicillin-cloxacillin. The resistance to commonly used antibiotics observed pose a public health risk to consumers of these products.

\section{RECOMMENDATION}

There is the need for effective control measures to safeguard public health from this food borne pathogen. This can be achieved through creating awareness to food vendors to adhere strictly to personal hygiene and avoid direct contact with the product especially when measuring. 


\section{REFERENCES}

Aboh, E.A., Giwa, F.J. and Giwa, A. (2015). Microbiological assessment of well waters in Samaru, Zaria, Kaduna State, Nigeria. Annals of African Medicine, 14(1): 32-38

Afroz, H., Sultana, F., Fakruddin, M., Kamrunnahar, Khan, Z.U.M. and Datta, S. (2013). Isolation of Escherichia coli and Staphylococcus aureus from full cream powder milk sold under market conditions at Dhaka, Bangladesh and their antibiotic susceptibility. Journal of Advanced Scientific Research, 4(3):27-31

Agboke, A.A., Osonwa, U.E., Opurum, C.C. and Ibezim, E.C. (2011). Evaluation of microbiology quality of some soybean milk products consumed in Nigeria. Prime Research on Medicine, 1(2):25-30

Ahmed, S. and Anwar, M.N. (2006). Microbial Contaminants of Dried Powder Milk Available in Local Markets of Bangladesh. Bangladesh Journal of Microbiology, 23(2):162- 164

Ateba, C.N., Mbewe, M., Moneoang, M.S. and Bezuidenhout, C.C. (2010). Antibioticresistant Staphylococcus aureus isolated from milk in the Mafikeng Area, North West province, South Africa.South African Journal of Science, 106(11/12):1-6

Ayele, Y., Gutema, F.D., Edao, B.M., Girma, R., Tufa, T.B., Beyene, T.J., Tadesse, F., Geloye, M. and Beyi, A.F. (2017). Assessment of Staphylococcus aureus along milk value chain and its public health importance in Sebeta, central Oromia, Ethiopia. BMC Microbiology, $17: 141 \mathrm{DOI}$ 10.1186/s12866-017-1048-9

Bashar, T. and Malek, M.A. (2006). Prevalence of microbial contaminants of some milk and milk products available in different markets of Dhaka. Bangladesh Journal of Microbiology, 23(1): 75-77

Cheesbrough, M. (2009). District Laboratory Practices in Tropical Countries. Part two, 2 Ed., Cambridge University Press, United Kingdom

Clinical and Laboratory Standards Institute (CLSI) (2015). Performance standards for antimicrobial susceptibility testing; twenty-fifth informational supplement, M100-S25, 35(3): 64-71

Foods Standards Australia New Zealand (2018). Compendium of Microbiological Criteria for

Food.P10https: / / www.foodstandards.g ov.au/publications/Documents/Comped ium\%20of20Microbiological\%20Criteria/ Compendium revised-Jan-2018.pdf Accessed on 29th October, 2019

Furtula, V.,Jackson, C.R., Farell, E.G., Barrett, J.B.,Hiott, L.M. and Chambers, P.A. (2013).Antimicrobial Resistance in Enterococcus spp.Isolated from Environmental Samples in anArea of Intensive Poultry Production. International Journal of Environmental Research and Public Health, 10:10201036

Le Loir, Y., Baron, F., and Gautier, M. (2003). Staphylococcus aureus and food poisoning. Genetics and Molecular Research, 2(1): 63-76

Mailard, J. Y. (2002). Bacterial target sites for biocideaction. Journal of Applied Microbiology, 82:53-60

Okpo, N.O., Abdullahi, I.O., Whong, C.M.Z. and Ameh, J.B. (2016). Occurrence and antibiogram of Staphylococcus aureusin dairy products consumed in parts of Kaduna state, Nigeria. Bayero Journal of Pure and Applied Sciences, 9(2): 225 $-229$

Poole, K. (2002). Mechanism of Bacterial Biocide and Antibiotic Resistance. Journal of Applied

Microbiology, 92: 55-64

Van Kessel, J.S., Karns, J. S., Gorski, L., McCluskey, B. J. and Perdue, M. L. (2004). Prevalence of Salmonellae, Listeria monocytogenes, and Fecal Coliforms in Bulk Tank Milk on US Dairies. Journal of Dairy Science, 87:2822-2830

Wouters, J.T.M., Ayad, E.H.E., Hugenholtz, J. and Smit, G. (2002). Microbesfrom raw milk for fermented dairy products. International Dairy Journal, 12(2-3):91109 